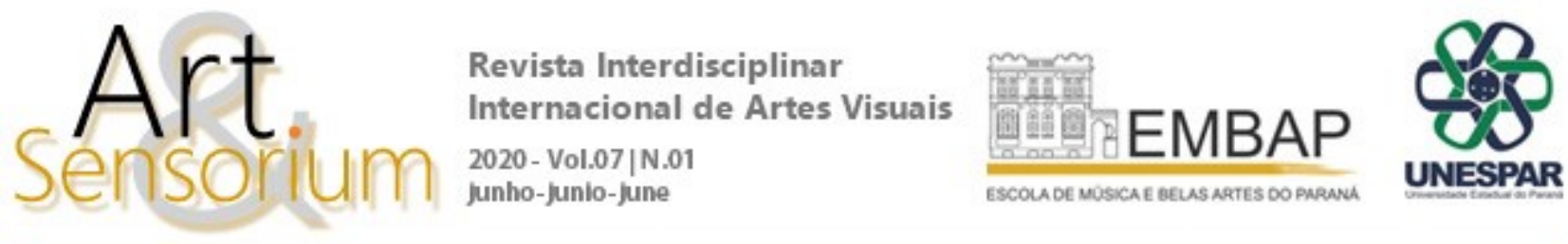

\title{
IMAGEM FIGURATIVA: \\ INTRODUÇÃO A UMA COMPREENSÃO HISTÓRICA E ANALÍTICA QUANTO AO CONCEITO, MEIOS E MODOS DE REPRESENTAÇÃO \\ DOI: https://doi.org/10.33871/23580437.2020.7.1.199-214
}

Marcillene Ladeira ${ }^{l}$

\begin{abstract}
Resumo: O presente artigo explana uma metodologia de ensino da disciplina "Perspectiva e Sombra", Curso Arquitetura e Urbanismo, UNIPAC/Barbacena, a qual se configura por dois pontos chave: a compreensão teórico-prática (história, conceito, meios e modos) e analítica - esta, com base em Montenegro (2005) foi formalizada através da aplicação de teste quali-quantitativo, cujo objetivo fora constatar como os discentes oriundos de uma cultura mass media enfrentam o problema de representação da tridimensionalidade no plano. No total, 88 alunos participaram da pesquisa. Entre outras questões, as conclusões evidenciam que o binômio "manual-tecnológico", ainda que em graus diferentes a depender das épocas, sempre coexistiu, não sendo uma característica exclusiva de agora. E, apesar de toda a facilidade vinda através das novas tecnologias, acaba sendo impraticável seu uso sem o alicerce da habilidade manual; e esta (por sua vez) deve ser fortalecida em uma construção conjunta entre percepção espacial e sensibilização criativa. Questões que qualificam a presença e permanência de uma disciplina cujo mérito está no ensino das habilidades manuais. Acrescenta-se, também, que na efetivação de uma pesquisa, ao se transformar em texto, há uma transposição dos níveis de sala de aula, tornando-se um instrumento de compartilhamento entre os pares.
\end{abstract}

Palavras-chave: imagem figurativa; manual-tecnológico; ensino-pesquisa; arte; arquitetura.

\section{FIGURATIVE IMAGE: \\ INTRODUCTION TO A HISTORICAL AND ANALYTICAL UNDERSTANDING OF THE CONCEPT, MEANS AND MODES OF REPRESENTATION}

\begin{abstract}
This article explains a teaching methodology of the discipline "Perspective and Shadow", Course Architecture and Urbanism, UNIPAC/Barbacena. Which is set up by two key points: theoretical and practical understanding (history, concept, means and modes) and analytical - this, based on Gildo Montenegro (2005), had formalized through the application of a qualitative-quantitative test, whose objective was to verify as students from an essentially mass media culture face the problem of representation of three-dimensionality in the plane. Eighty-eight students participated in the survey. Among other issues, the conclusions show that the "manual-technological" binomial, although in different degrees depending on the times, has always coexisted, not being an exclusive feature of the now. In addition, despite all the ease coming through the new technologies, ends up being impractical to use without foundation of manual skill; and this (in turn) must has strengthened in a joint construction between spatial perception and creative awareness. Issues that qualify the

\footnotetext{
${ }^{1}$ Pesquisadora e Professora do Centro Universitário Presidente Antônio Carlos (UNIPAC/Barbacena/MG). Mestra em "Processos Experimentais na Arte Contemporânea" desenvolvido no Programa de Pós-Graduação em Artes Visuais, Escola de Belas Artes, Universidade Federal da Bahia; especialista em Docência do Ensino Superior pelo Instituto Pedagógico de Minas Gerais; Graduada (Licenciatura e Bacharelado) em Arte pelo Instituto de Artes e Design da Universidade Federal de Juiz de Fora, com passagem inicial pela Escola de Belas da Universidade Federal do Rio de Janeiro; Técnica em Informática pelo Instituto Federal de Educação, Ciência e Tecnologia. Líder do grupo de pesquisa "VEIA" - Vertentes Ensinagem Integração e Arte, cuja proposta de pesquisa se desenvolve através de parcerias institucionais: Centro de Ciências/UFJF e UNIPAC através do Programa de Iniciação Científica; membro do grupo "MAMETO CNPq - Matéria, Memória e conceiTO em Poéticas Visuais Contemporâneas (PPGAV/EBA/UFBA). Possui publicações a nível nacional e internacional. E-mail: marcilleneladeira@unipac.br
} 
presence and permanence of a discipline whose merit is in the teaching of manual skills. It is also has added that the accomplishment of a research, when transformed into text, there is a transposition of the classroom levels, becoming an instrument of sharing among peers.

Keywords: figurative image; technological manual; teaching-research; art; architecture.

\title{
IMAGEN FIGURATIVA: \\ INTRODUCCIÓN A UN ENTENDIMIENTO HISTÓRICO Y ANALÍTICO SOBRE EL CONCEPTO, MEDIOS Y MODOS DE REPRESENTACIÓN
}

\begin{abstract}
Resumen: Este artículo explica una metodología de enseñanza para la disciplina "Perspectiva y sombra", Curso de Arquitectura y Urbanismo, UNIPAC/Barbacena, que se configura mediante dos puntos claves: comprensión teórica y práctica (historia, concepto, medios y modos) y analítico: basado en Gildo Montenegro (2005), se formalizó mediante la aplicación de una prueba cualitativa/cuantitativa, cuyo objetivo era verificar cómo los estudiantes de una cultura de 'mass midia' enfrentan el problema de la representación de la tridimensionalidad en el plano. En total, 88 estudiantes participaron en la investigación. Entre otras cuestiones, las conclusiones muestran que el binomio "manual-tecnológico", aunque en diferentes grados dependiendo de los tiempos, siempre ha coexistido; No es una característica exclusiva del ahora. A pesar de toda la facilidad que aportan las nuevas tecnologías, nos es práctico su uso sin la base de la habilidad manual; y esto (a su vez) debe fortalecerse en una construcción conjunta entre la percepción espacial y la conciencia creativa. Preguntas que califican la presencia y permanencia de una disciplina cuyo mérito está en la enseñanza de habilidades manuales. También se añade que la realización de una investigación, cuando se transforma en texto, hay una transposición de los niveles del aula, convirtiéndose en un instrumento de intercambio entre pares.
\end{abstract}

Palabras Clave: imagen figurativa; manual tecnológico; enseñanza-investigación; arte; arquitectura.

\section{INTRODUÇÃO}

A prática, o ensino e a teorização da expressão gráfica, enquanto imagem figurativa, foram e continuam sendo alvo de profundos debates críticos, especialmente nos cursos superiores que lidam com tais áreas, entre estas, as Artes Visuais e a Arquitetura.

O fato é que, desde os anos de 1960, vivemos em uma cultura de mass media, na qual a apropriação, a divulgação e a própria produção das imagens acontecem de forma vertiginosa, isto é, a partir desse período, as mudanças tecnológicas vêm acentuando consubstancialmente e atingem níveis surpreendentes, de modo que o ensino dos meios e modos de representações realizados pelas mãos sofre abalos significativos; muitas vezes, acabam ficando ofuscados por "softwares" próprios para edição de imagens, que as geram (e até as modelam) quase que "automaticamente". Disso resulta nos situarmos, hoje, em uma nova redefinição da relação espaço-tempo ${ }^{2}$ da representação.

$\mathrm{O}$ referido estudo surge (então) dessa perspectiva de reflexão e acaloramento do debate quanto à presença e uso da imagem figurativa no mundo, sobretudo ao seu ensino. Isso está para mim, como uma inquietação que se originou nas próprias vivências experimentais. Em um primeiro momento, diz-se do emprego enquanto expressão pictórica autoral trabalhada na graduação e pós-graduação ${ }^{3}$, passando-se ao ensino do desenho no sistema educacional brasileiro. Ao assumir a pintura figurativa (uma das possibilidades de aplicação da figuração) como linguagem norteadora do trabalho em Artes Visuais, deparei-me com um ferrenho debate teórico quanto à sua pertinência; mas respaldada em

\footnotetext{
${ }^{2}$ Diz-se, de uma nova consciência histórica.

${ }^{3}$ Cumpre observar que tal uso, na verdade, antecede o próprio nível superior: antes mesmo do ingresso na graduação já atuava como professora em atelier (Petrópolis/RJ, 2005-2008) - experiência que se tornou um profícuo laboratório.
}

R. Inter. Interdisc. Art\&Sensorium, Curitiba, v.7, n.1, p. 199 - 214 Jan.- Jun. 2020 
autores como Deleuze (1925-1995), a exemplo, encontrei a seguinte afirmação: “[o ser] deve antes de tudo se empenhar em restituir a singularidade dos pensadores que o precederam para, uma vez nutrido e mais bem armado com o pensamento de outro, se lançar em um trabalho de criação pessoal". (DOSSE, 2010, p.97). Portanto, o lastro contido na historicidade da representação não se passou como um empecilho, mas um trampolim bem instalado, no intuito de se dar um salto adiante. Agora, como professora universitária nas disciplinas de "Desenho Artístico à Mão Livre" e "Perspectiva e Sombra" no curso de Arquitetura e Urbanismo do Centro Universitário Presidente Antônio Carlos (UNIPAC/Barbacena) e a consequente necessidade da instrução efetiva de técnicas de representação da imagem figurativa, afloram-se novas tensões, as quais serão trabalhadas no decorrer.

Assim, o presente artigo, refere-se a um dos recortes do assunto que vem se apresentando. O texto está estruturado em tópicos e subtópicos, cuja preocupação externa-se tanto na compreensão conceitual (tópico 2 - ênfase nos pontos da mímesis: Naturalismo, Idealismo e Expressionismo), histórica (3-subdividindo-se em evolução manual e tecnológica), e, por fím, analítica (4). O último, apresenta-se em forma de teste quali-quantitativo aplicado em nível de graduação (34 alunos) e de educação básica - formação imediatamente anterior àquela (54 alunos). (SEVERINO, 2007, p.118). O objetivo desse teste está em constatar como os alunos enfrentam o problema de representação da tridimensionalidade, uma vez que, como afirma Gildo Montenegro (2005, p. 4), a análise sobre os resultados permitem penetrar no pensamento e analisar os processos mentais. O referido pesquisador chama a atenção para a deficiência que os graduandos normalmente trazem consigo, mediante ao fato da carência de uma disciplina específica de Desenho, cursada ao longo de sua vida estudantil, tendo essa sido retirada da educação básica. Atualmente, há o conteúdo de Arte e de Geometria (a cargo da Matemática); ambas, pela grande extensão do conteúdo a ensinar, muitas vezes não dão conta, ou não se atentam para tal significância e a falta dessa base afeta diretamente o aluno no nível superior.

\section{IMAGEM FIGURATIVA: UM CONCEITO?}

Diferentemente das pinturas figurativas, estão as obras de arte abstratas, isto é, os processos artísticos nos quais as tintas se espalham sobre um suporte, sem nenhuma forma reconhecível. Comentários comuns sobre essas obras, estando presente até mesmo em sala de aula, são as indagações, seguindose da expressão: "há, isso até eu faço?"; ou da pergunta: "Por que os altos preços pagos por elas?"; ou, até mesmo, críticas fervorosas postas na arte moderna, no momento, imediatamente, anterior à abstração total, a qual levou à figuração à grandes distorções.

Também é com frequência que ao desafiar as pessoas a realizarem certas representações figurativas, as mesmas afirmarem não serem capazes, não possuírem dom para o tal ato. Observa-se que Marcondes (1998, p.125), em seu dicionário de Termos Artísticos, define figuração como a "representação plástica que mostra formas reconhecíveis [...] ainda que estejam bastante interpretadas e não necessariamente reproduzidas de maneira acurada. O oposto de abstrato".

Na compreensão dessa dimensão, observada sob o olhar de diferentes autores, há uma premissa implícita, culturalmente, de que a arte em sua conduta de representatividade seja essencialmente imitativa, via expressão "cópia da natureza" ou através do conceito de mímesis ou mimese - "é dessa forma que interpretamos a conhecida afirmação de que 'a arte imita a natureza", como assim expressa Carlos de Almeida Lemos (2009, p.84), a exemplo. O referido autor explica que o conceito originase nos filósofos gregos, Platão e Aristóteles; desde a antiguidade, Aristóteles em oposição a seu mestre Platão, ao dizer sobre a mímesis, em lugar de associá-la ao falso e enganoso, vai dizer que "a imitação da natureza por parte da arte não é um retratar, realizar uma simples cópia do real, mas um fazer como, produzir à maneira de". Isto é, Aristóteles vê a imitação positivamente, considerando-a como um modus operandi. (LEMOS, 2009, p.84-90). 
O mesmo olhar positivo a favor da mímesis é trazido no Renascimento; José D’Assunção Barros (2008, p. 76) explica que Leonardo Da Vinci concebia a Arte como uma "Ciência da representação da Natureza", o que habilita expressar: "imitação científica da Natureza", em oposição à "imitação mecânica". Nas próprias palavras de Da Vinci: "arte é coisa mental". Nesses termos, tanto "o Cientista, como o Artista, deveria ser um observador e um experimentador e os sentidos deveriam ter um papel fundamental tanto em uma como em outra destas formas de apreensão da realidade". Na arquitetura, esse processo poderia ser identificado, a exemplo dos dias atuais, no que se chama de "Metabolismo", cuja inspiração formal e conceitual encontra-se em organismos vivos.

Porém, vale lembrar que, como pondera Fayga Ostrower (2004, p.314), o artista (ou outra pessoa que representa) e quaisquer que sejam as imagens produzidas, na verdade, substituem as formas existentes na natureza e seus contextos, por outras "formas humanas", por assim dizer. Isto é, mesmo querendo inspirar-se nas formas da natureza, o homem as transforma em uma "forma de linguagem". Ao determinar a representação, por exemplo, de um "ser folha", oriunda do universo natural, junto à faixa de percepções e emoções humanas, no ...

[...] organismo vivo da folha em termos formais, o artista inventa linhas para representar o que na natureza seria a bainha da folha, ou suas nervuras, ou sua haste, ou planos diferentes no espaço, assim como inventa certas relações de cores para descrever o calor e a luz solar, a clorofila na química da vida, as horas e os tempos do dia. (OSTROWER, 2004, p.314).

$\mathrm{Na}$ continuação dos apontamentos da autora, tal transformação (natureza-linguagem) é fortalecida por determinadas variantes, a saber: 1.muda-se a linguagem de acordo com cada especificidade do material operado; 2.difere-se a cada tempo histórico, sobre os quais derramam os valores vigentes e projetam-se os estilos; 3.há, ainda, atitudes quer, suficientemente, isoladas ou individuais que representam maneiras diversas de se encarar e elaborar o que se pretende. Seria como se dentro do estilo próprio de cada época, mediante a presenças múltiplas, coexistisse forças individuais. 4.nesse todo: paira, de igual modo, diferentes áreas operantes (assim completo).

Em termos de estilo e historicidade, o Naturalismo, o Idealismo e o Expressionismo, como define Max Deri (apud OSTROWER), distinguem-se como três grandes terminologias que unem os inúmeros padrões cronológicos. De modo poético, como à luz de Fayga, seria: na abrangência de um único oceano, há três grandes correntes submarinas que moldam o curso das demais ondas. Nenhuma delas se excluem mutuamente; por vezes, se interpenetram; contudo, ainda representam atitudes suficientemente reconhecíveis e distintas. Na identificação, a primeira forma de representação (Naturalismo) está para o respeito em manter a configuração natural com fidelidade, mesmo que haja deformações; a segunda (Idealismo) entra o que se chama de generalização; e a terceira (Expressionismo), funda-se na "intensificação de nossas emoções".

Ao tornar-se mais explícito: um desenhista naturalista, ao retratar uma árvore, escreve Fayga, "reproduziria o tronco com as irregularidades incidentais que possam ocorrer na natureza", "procuraria captar e reproduzir certos detalhes que distinguisse essa árvore de outras semelhantes". O idealista, "procuraria reduzir, ou mesmo omitir, certos detalhes individuais, indicando na imagem apenas características gerais [e comuns a todas as árvores]: verticalidade, altura e grossura do tronco". O expressionista, seleciona para sua representação apenas aqueles detalhes que considera essenciais do ponto de vista emotivo, podendo transformá-los de maneira vultuosa, como galhos de pontas que furam o céu e cores altas que criam grandes contrastes. (OSTROWER, 2004, pp.313-321).

\footnotetext{
${ }^{4}$ Movimento iniciado em 1960, Tóquio/Japão; refere-se a criação de projetos biomórficos. (DENISON,2016, p.114).
} 
Vale frisar que os três modos, ainda que haja certa distinção, referem-se à representação de caráter figurativo ou mímesis, visto tratar-se de "formas reconhecíveis"; sendo tais diferenciações de suma significância, ao se operar em projetos de criação evidenciados na arquitetura.

\section{PELOS CAMinhos deSEnhantes da históRia: MEIOS E MÉTOdOS DE REPRESENTAÇÃO}

Nossos mais remotos ancestrais, os povos chamados primitivos, entre estes "o homem Aurinhacense", talvez tenha sido o primeiro a fazer arte não aplicada. Muitos pesquisadores, entre eles, os arqueólogos, chegaram até a contestar a datação de certos desenhos, por serem muito avançados, como a complexidade das curvas e detalhes de ursos, rinocerontes e cavalos da caverna Chauvet, no Sul da França, sendo a mais antiga do mundo (28.000 a 40.000 anos atrás).

De lá para cá, a habilidade de representação da tridimensionalidade no plano trilhou por inúmeros estudos, sendo hoje um território mapeado e conhecido. Gildo Montenegro (2005) a compara a uma cordilheira de montanhas, que apresentam certos montes ou pontos culminantes, os quais seriam as teorias já desbravadas e aplicadas. No entanto, o professor compreende que exista (também) os montes com domínios ainda não desbravados, bem como os intermediários - aqueles reservados "à fantasia" ou "intuição pura". Seria, a exemplo, como no desenho de uma criança ou até mesmo no mundo dos adultos que desenvolvem certas práticas (por vezes), desconhecendo o sistema teórico ou (ao conhecer) amplia o mesmo - como, assim, completo. Ver-se-á: um homem pode realizar o ofício de jardinagem sem um estudo sistemático; por outro lado, há aqueles que mesmo tendo o arcabouço teórico como base não é suficiente, sendo necessária, por vezes, a intervenção do "eu" - desse intelecto intuitivo e único - é isso que nos lança em novas teorias.

Com vistas no desvelamento desses caminhos trilhados, os próximos subtópicos dividem-se em duas vias: o andar da representatividade via habilidade manual e quanto ao uso de tecnologias.

\subsection{O sistema de projeções e o desenvolvimento das habilidades em traços manuais}

Projeção no dicionário define-se como "o que é projetado ou lançado"; “ação de projetar". Saindo de nós está o olhar, é esse que se lança ao alcance na imagem a ser representada. Parece que a natureza nos consegue demonstrar naturalmente o raio visual desse campo, seja em nós (sistema ocular/visão), seja no meio externo a nós, como escreveu Aristóteles (384-322 a.C.) ainda no século IV a. C. O exposto tratou-se da observação e descrição de um eclipse parcial da lua; o filósofo explicou como se formava as imagens no chão, a partir do momento em que os raios de luz se projetavam através de pequenas fendas entre as folhas. Os gregos se beneficiaram dessa observação para criarem sistemas ilusionistas de representação. No primeiro momento, aplicou-se, a exemplo, em cenários pintados nas paredes para decoração de palácios e templos. Experimentação intuitiva da pré-história (pintura rupestre, conforme já relatado), sendo continuada, posteriormente, como na obra "A Vida na Cidade", pintura a fresco de Ambrogio Lorenzetti (1290-348), Idade Média. (HOCKNEY, 2001; SMITH, 2003).

Ray Smith (2003, p.351) nos indica que o tratado teórico que teve mais influência no desenvolvimento do sistema de projeção está no livro Óptica, de Euclides de Alexandria (Egito, período helenístico), escrito cerca de 300 a.C. O intelectual investigou a "experiência visual" e, diferentemente do estudo dos gregos, reduziu o ato de ver a uma consideração geométrica, na qual o olho passa-se a um ponto que se localiza no vértice de um cone - o cone visual. Tal análise passou a constituir-se como uma ciência da perspectiva, com aplicação na prática manual. Ou de outra forma, Saito (2008) disserta o 
estudo como sendo a primeira elaboração em torno do que, hoje, denominamos de "óptica geométrica" ou "ciência óptica". Todavia, a obra Óptica de Euclides teve uma durabilidade modesta, em comparação à outra do mesmo: Os elementos. A última (tratado matemático e geométrico) constitui-se de 13 livros, vigorou até o final do século XIX. Referido, muitas vezes, como o "Pai da Geometria", Euclides teria nascido no século III a.C. e morrido em data desconhecida.

Desse processo, outro texto que pode ser destacado pertencente ao patrimônio antigo, está o De Architecture, de Marcos Vitrúvio, escrito aproximadamente em 25 a.C. Em uma publicação no Brasil em competente e cuidadosa tradução, extrai-se um recorte:

A geometria, por sua vez, proporciona à arquitetura muitos recursos. Em primeiro lugar, logo a seguir às linhas retas, ensina o uso do compasso, com o qual se efetuam muito mais facilmente as representações gráficas dos edifícios nos seus próprios locais, juntamente com a ajuda dos esquadros, dos níveis e dos direcionamentos de linhas. Em segundo lugar, porque, através da óptica, se orientam corretamente os vãos de iluminação nas construções, a partir de determinadas zonas da abóboda celeste. (VITRÚVIO POLLIO, 2007, p. 63).

Pela leitura do texto, tem-se uma menção direta à aplicação da ciência óptica e geométrica no processo dos arquitetos, isto é, no desenho de plantas dos edifícios. Observa-se, ainda neste estudo, a seguinte instrução: "a ciência do arquiteto é ordenada de muitas disciplinas e de vários saberes" (p.61). "Convém que o arquiteto conheça a arte literária, para que possa deixar uma marca mais forte através de seus escritos" - como fez o próprio Vitrúvio, tornando-se presença viva desde aquele momento até aos dias atuais; "também deverá ser instruído na ciência do desenho, a fim de que disponha da capacidade de mais facilmente representar a forma que deseja para suas obras, através de modelos pintados" (p.63). Geometria, Aritmética, entre outras, incluem-se nessa instrução.

Após o período romano, Ray Smith (2003, p.352) evidencia que o uso da perspectiva deixou de existir durante quase mil anos, ressurgindo, novamente, na Europa do século XIII, com a tradução, ao latim, do manuscrito de Alhazan (965-1038) - erudito árabe que introduziu ideias novas, comparando-se às anteriores. (Cf. HOCKNEY, 2001, p. 202-225; SMITH, 2003, 351-357).

Outros nomes seguiram ao de Alhazan, a exemplo de Roger Bacon (1212-1294), Witelo (1275-?) e John Pecham (1230-1292), este com o tratado intitulado "Perspectiva Communis", escrito por volta de 1270. A ligação deste com a Igreja (arcebispo) certamente facilitou a difusão de suas ideias (tendo em vista a Santa Inquisição5), tornando-se o manuscrito mais lido e adotado em toda a Europa, mesmo antes da imprensa de Gutenberg, por volta de 1430. Estima-se 73 publicações dessa compilação6, sendo 62 manuscritos e 11 impressões, além de outras bibliografias que a cita; eis o nome "Communis", que quer dizer "de uso comum". (HOCKNEY, 2001).

Em 1425, pleno Renascimento, Filippo Brunelleschi, artista e arquiteto italiano, demonstrou o sistema de perspectiva central, na qual todas as ortogonais convergem para um ponto de fuga a depender do ângulo de vista do observador. Uma década após, 1435, surge o tratado De Picture, de Leon Battista Alberti. Saito (2008), à luz de Erwin Panofsky (1993 [1927], pp. 36-38), nos explica que seu autor, Alberti, foi o responsável por codificar uma contradição (imprecisa) existente nos estudos de Euclides - a chamada "perspectiva antiga" ou "perspectiva natural", quanto em comparação à nova versão: "perspectiva renascentista" ou "perspectiva artificial" - o que justificaria a vida curta do tratado

\footnotetext{
${ }^{5}$ Espécie de tribunal religioso (Tribunal do Santo Ofício da Inquisição), fundado pelo Papa Gregório IX na Idade Média, o qual condenava (manda para a fogueira) todos os que eram contra os dogmas pregados pela Igreja Católica (os hereges). ${ }^{6}$ Manuscritos: um do século XIII, 29 do século XIV, 26 do século XV, duas do século XVI, um do século XVII e três sem datas; Impressões: uma em 1482 ou 83, nove vezes no século XI (sendo uma em italiano) e outra em 1627.
} 
intitulado "Óptica" e a adoção do novo processo pelos artistas e arquitetos da época. A exemplo de uso, cita-se o fresco "A Trindade”, basílica de Santa Maria Novella, Florença/Itália.

Leonardo Da Vinci (1452-1519), embora não tenha colocado seu princípio em prática, apontou possíveis diferenciações, estando a "perspectiva renascentista" em um sistema explicitamente linear e, portanto, artificial, enquanto a "perspectiva antiga" em um sistema curvilíneo. A inexatidão do segundo estaria em apresentar o sistema curvilinear em toda a extensão como numa reta, em vez de relacionar-se com o ângulo de visão, perfazendo um arco convexo e, portanto, variável. A rigor, esse sistema apresentaria (então) uma experiência mais natural aplicada ao uso da perspectiva ou representação tridimensional no plano - eis a diferenciação dos nomes. (SMITH, 2003).

Na continuidade, em 1505 é apresentado o tratado De Artificiali Perspectiva, do monge e diplomata francês Jean Pélerin Viator (1445-1524), o qual introduz o conceito de "ponto de distância" ao processo da perspectiva, ou seja, outros pontos de fuga além do central. Viator se destaca, também, por ter sido membro fundador de uma "associação cultural e científica", datada de 1500, a Gymnasium Vasagense, o que confirma "arte e ciência" trabalharem como parceiras. Na continuidade dos estudos, em 1600, o matemático italiano Guido Ubaldo del Monte (1545-1607) acrescentou o traço de uma linha paralela a partir do olho - a linha do horizonte. Em meados do século XVII, nasce o sistema de representação com três pontos de fuga. No final do século, o mesmo já se tornaria merecedor de confiança. A título de enobrecedora representação, cita-se a obra "A Glória de Santo Inácio" (16911694), realizada pelo Padre Andrea Pazzo, no teto abobadado da Igreja de Santo Inácio, em Roma, a qual se beneficiou de um articuloso sistema de grelha com corda, alternando-se o ponto de vista ao nível da abóboda e do chão, com vistas ao ângulo do teto. (SMITH, 2003; BRION-GUERRY, 1962).

Quanto à continuidade do processo da "perspectiva natural", Hockney (2001, p. 209) aponta a publicação, em 1558, do tratado A Magia e Naturalis do italiano Giambattista Della Porta (15351615). O livro fora o mais abrangente relato de projeções antes do século XVIII; a primeira edição continha quatro volumes e a segunda (1588) expandiu-se para 20 volumes.

Entre outros aspectos da representação da tridimensionalidade no plano pelas mãos, a "perspectiva atmosférica" ou "aérea" está entre a que define a colorização da imagem. Apresenta-se pelo efeito de arrefecimento das cores à medida que se afasta em direção ao horizonte, dado pelo uso de escalas tonais: quanto mais perto do observador mais vívido o tom, tornando-se mais claro, com o devido afastamento e a sobreposição dos planos. O ar nevoento é impresso pela tom azulado. (SMITH, 2003, p.357).

\subsection{O sistema de projeções e os aparatos tecnológicos voltados para o desenvolvimento das técnicas de representação da tridimensionalidade no plano}

O termo tecnologia (do grego tecno+logia) está para, techné: "saber fazer" e logus: "razão", configurando-se como: "razão do saber fazer". Em busca da profusão desse conceito Veraszto et al (2008, p.61) realiza uma revisão histórica e propõe uma definição atual e norteadora, assumindo a ideia de que "tecnologia é um conjunto de saberes desenvolvidos (artefatos, sistemas, processos e ambientes) pelo homem através da história para satisfazer suas necessidades pessoais e coletivas". Sua presença acaba por modificar todo um conjunto de costumes e valores por ela envolvido. Na especificidade do contexto artístico ou, em outras palavras, no processo representacional da imagem no plano, os professores Milton Sogabe e Rosangella Leote (2012, p.46) afirmam que sempre esteve presente, desde as primeiras manifestações humanas, relacionando a graus diferentes a depender das épocas. Por essa via, passar-se-á a penetrar nos artifícios dos antigos mestres da história, os quais nos levam a compreender que muitos desses gênios não se valeram, apenas, da vista desarmada para representarem suas obras. O artista britânico David Hockney, uma das referências atuais no assunto, partindo-se de provas visuais (exemplo Figura 1), acabou por se debruçar nesse caminho misterioso, 
rastreando, obsessivamente, tais segredos, conforme consta no livro "O Conhecimento Secreto: redescobrindo as técnicas perdidas dos grandes mestres”, publicado em 2001.
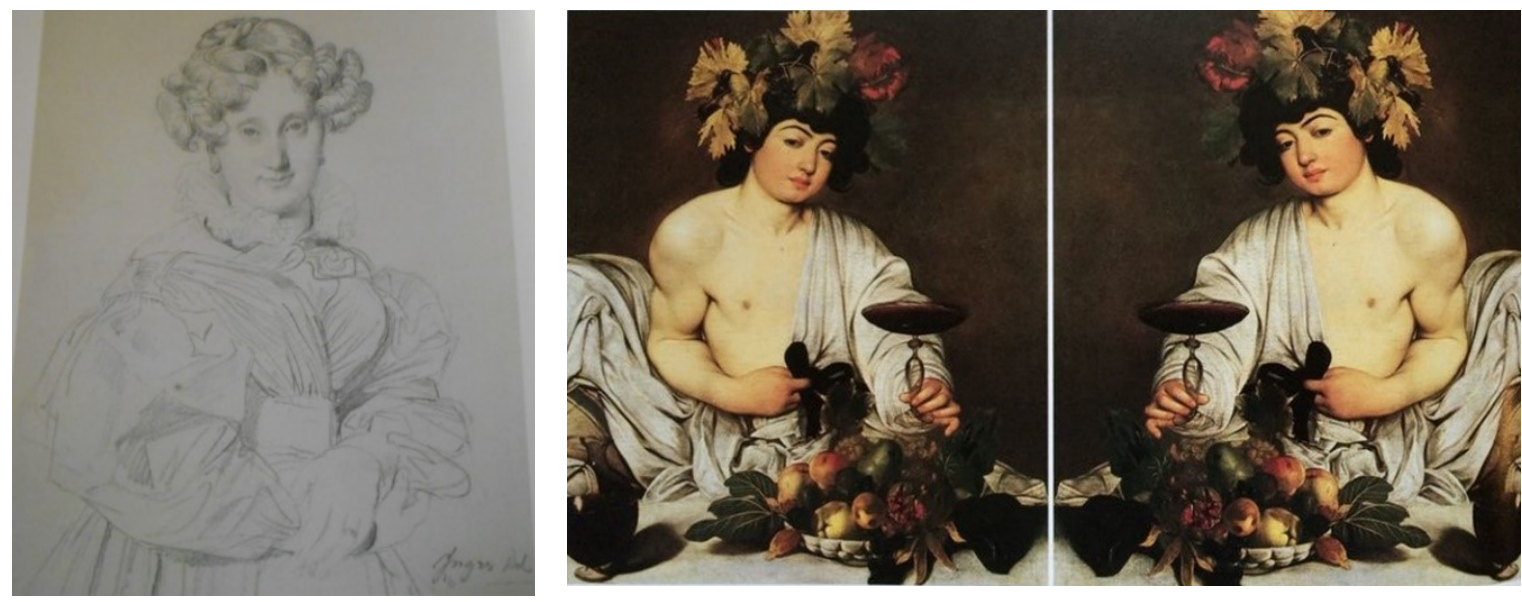

Figura 1- Representação por Ingles e por Caravaggio, respectivamente Fonte-HOCKNEY, 2001, páginas 23 e 118

A primeira imagem da Figura 1, refere-se ao retrato de Madame Louis-François Godinot, realizado por Ingres em 1829; em via de regra, o desenho é o primeiro passo no processo da pintura. Quanto a essa, um dos pontos que sugere a exploração do instrumento tecnológico, estaria no aumento de 8\% da cabeça em relação ao corpo, provocado, possivelmente, pelo deslocamento do dispositivo. Já a segunda obra, retrato de Baco, de 1595, é uma pintura óleo sobre tela do mestre barroco italiano M. Caravaggio (1571-1610). Quanto a essa, observa-se que a versão da esquerda é a obra dada pelo artista e a da direita, uma "imagem especular". Hockney assim apresenta por acreditar ser ela mais natural e harmoniosa (modelo destro e não canhoto) que a imagem da esquerda. Nessas condições, o desenho teria sido produzido (então) através de um aparelho óptico. Além desses, ao longo do livro, muitos outros exemplos curiosos são discutidos, entre os quais estão, certamente, referências específicas da arquitetura, a exemplo da retratação da "Catedral de Colônia", por Andy Warhol (ambiente externo, p.123) e "São Jerônimo em seu gabinete" (ambiente interno, p. 99).

Para o artista-pesquisador britânico a resposta ou "o segredo" (como expressa no título de seu livro) efetiva-se pela presença de uma "lente" junto ao buraco de projeção dos aparelhos ópticos. Em trechos retirados de um dos livros da antiguidade: “A Magiae Naturalis", por Della Porta, há:

Agora, eu revelarei aquilo que estava oculto até agora e o que pensei sempre ocultar. Se colocares uma lente cristalina no buraco, verá logo todas as coisas mais nítidas; a fisionomia dos homens que caminhas, as cores, as vestes, o movimento e todas as coisas como se estivesses perto; [...] o que está à direita estará à esquerda e [...] quando mais longe distarem do buraco, tanto maiores aparecerão. Se aproximares o papel [...] as coisas se mostrarão menores e mais nítidas. (SAITO, 2008, p.124).

Na realidade, a partir do século XVI, muitos outros autores passaram a citar esse dispositivo. Saito (p. 125) lista: "Erasmo Reinhold (1511-1553), Gemma-Frisius (1508-1555), Jean-François Nicéron (1613-1646), Johan Zahn (1631-1707)" e antes mesmo de "A Magiae Naturalis", há De subtilitate libri XX, de Cardano (1550), a qual o próprio Della Porta chegara a fazer referência.

Hockney, por sua vez, apresenta em seu livro inúmeras variantes do dispositivo ao longo dos tempos. O primeiro deles, construído ainda na antiguidade clássica e sendo de grande formato, estaria para o "quarto câmara escura". Seguindo-se pelos finais do século XVIII e início do XIX, Ray Smith aponta as versões caseiras; estas, variavam em forma de tenda e cadeirinha, podendo ser instaladas em 
qualquer situação, desde que o interior fosse muito escuro e o exterior com muita luz. Nomes como caixa câmara escura e câmara clara foram adotados; esta seria mais avançada que aquela e dispensava a escuridão total. Smith explica que a primeira versão da câmara clara data de 1806, dada pelo inglês Dr. W. H. Wollaston. Em 1811, Cornelius Varley cria o telescópio gráfico; mais recentemente, poder-se-á citar a invenção do "retroprojetor de lâminas", chegando-se à "projeção digital" via computador. (Cf. HOCKNEY; SMITH). A fotografia estaria em um modo próprio na qual a imagem foi fixada sobre o suporte, sem necessidade do traço humano e os "softwares" de edição de imagem, por extensão ${ }^{7}$, caberia em uma ampliação mais complexa da habilidade representacional decodificada em linguagem de máquina (zero e um).

Ao voltar aos grandes mestres da pintura, mais especificamente na Holanda, no período conhecido como "O Século de Ouro da Pintura dos Países Baixos" (1584 e 1702), ver-se-á a análise de Marlon César de Alcântara - jovem físico brasileiro que, em sua pesquisa de pós-graduação (2011), partiu para a Europa à procura de esclarecimentos mais profundos. Marlon explica que nem tudo fora "luzes" pela Europa. Fugidos da repressão religiosa (Santa Inquisição) ${ }^{8}$ e política (repúdio a Felipe II, rei da Espanha que a cada dia aumentava a cobrança de impostos) e com a conseguinte "Guerra dos 80 anos", as terras de domínio espanhol se dividiram ${ }^{9}$. A parte sul, obteve independência em 1579, com reconhecimento em 1648. Esse novo lugar, denominado Holanda, passou a ser o refúgio de liberdade do pensamento europeu, tornando-se uma grande potência. Instalou-se ali, uma rede de relacionamentos muito forte, sendo parte desta, personalidades como: "Constantijn Huygens, o físico Christiaan Huygens, o filósofo Francis Bacon, o microscopista Antonie van Leeuwenhoek, o pintor JohannesVermeer, o inventor CorneliusDrebbel, os filósofos Baruch Spinoza, René Descartes", entre outros. A província, recém-liberta, entre outras atividades passou-se à fabricação e ao aperfeiçoamento de lentes, sendo esta, uma das atividades econômicas de destaque. $\mathrm{O}$ fabrico ia desde as macro, até as micro, sendo acopladas a equipamentos que habitavam tanto laboratórios como ateliês. O impacto na representação da imagem tridimensional no plano foi imediato: proliferaramse nos livros, nos mapas, quadros, porcelanas... Tudo era motivo de representação através da imagem e, certamente, estava bem mais fácil de ser executada. Por essa via, passa-se a entender a grande presença de pintores/desenhistas em terras germânicas: "estima-se que, de uma população que, no século XVII chegava a cinco milhões de pessoas, dois milhões eram pintores ou sabiam alguma técnica de pintura" - como assim explica o pesquisador. (Cf. ALCANTARA, 2011, passim).

De resto, as palavras abaixo, professadas pelo Conde italiano Francesco Algarottiem 1764 e citada por Hockney, demonstra o estado de maravilha diante do invento e, a tal modo, explica o uso:

Como este olho artificial (essa magnífica operação da natureza, cuja descoberta fora reservada a nossos tempos), não permite o ingresso de nenhum raio de luz; salvo aqueles procedentes da coisa cuja representação se quer [...]; e, não sendo nada mais encantador de contemplar, nada pode ser mais útil de estudar que tal imagem. [Sua] faculdade visual aplica-se integralmente ao objeto à sua frente. (HOCKNEY, 2001, p. 213).

Ao prosseguir-se no trecho, o Conde comprova o referido uso pelos artistas de sua época e, assim, escreve: "os melhores pintores modernos entre os italianos serviram-se amplamente deste invento; nem seria possível que de outro modo representassem coisas com tamanha fidelidade." (p. 214).

\footnotetext{
${ }^{7}$ Conceito adotado pela estética contemporânea, estando inicialmente em Rosalind Krauss, no célebre texto: Sculpture in the expanded field, publicado em 1979e traduz-se como "forma expandida" ou "ampliada" a depender da tradução.

${ }^{8}$ Espécie de tribunal religioso (Tribunal do Santo Ofício da Inquisição), fundado pelo Papa Gregório IX na Idade Média, o qual condenava (manda para a fogueira) todos os que eram contra os dogmas pregados pela Igreja Católica (os hereges). ${ }^{9}$ Pertenciam a este domínio terras que incorporavam "desde a Espanha até grande parte da Itália, chegando aos Países Baixos - Holanda, Bélgica e parte do norte francês -, além de territórios conquistados na América, África e Ásia”.
} 
Ainda no mesmo trecho, o Conde relata o esplêndido encontro de um mestre da pintura conhecendo a invenção pela primeira vez:

Aconteceu de eu estar presente quando um mestre muito hábil foi apresentado a essa máquina pela primeira vez. É impossível exprimir o prazer que teve em examiná-la. Mais a considerava, mais parecia encantado com ela. Em suma, após experimentá-la de mil formas diversas, e com mil modelos diferentes, ele confessou candidamente que nada se podia comparar com as imagens de tão excelente e imitável mestre. (HOCKNEY, 2001, p. 214).

Diante do exposto, parece que outra realidade se apresenta, pois acreditou-se, por muitos anos, que o desenho das pinturas dos grandes mestres fora executados somente, pelo traço à mão livre. Porém, frente à comprovação de aparatos tecnológicos, é notório observar que o referido uso não desmerece a genialidade dos artistas. Saber-se-á como terminam as palavras do Conde Algarotti: "os pintores devem fazer uso do aparelho da mesma maneira que os naturalistas e astrônomos fazem do microscópio e telescópio": como um "mero instrumento de trabalho". Não obstante, e compartilhando com Hockney, de minha própria experiência, firmo não ser tão fácil a referida utilização, uma vez que a imagem projetada não é, de todo, real - somente parece estar ali. Para seu uso efetivo, o traço deve ser rápido e cauteloso, com a fixação de um ponto de vista, ainda assim, as distorções são quase inevitáveis. Comparando-se o desenho do retrato humano às paisagens e à natureza morta, estas se tornam mais fáceis, devido ao caráter de identidade pessoal que aquele exige. Basil Hall (citado por RAY SMITH, 2003, p.361), "oficial da marinha que viajou na América do Norte nos finais de 1820, utilizando-se da câmara clara para realizar seus desenhos", cujo resultado foi publicado no livro, com data de 1830, de igual modo, afirmou: quem não tiver aptidão para o desenho, não consegue desfrutar do benefício da projeção. Esse estudo defende que a mesma condição estaria para os "softwares" de edição de imagens dos dias atuais.

\section{COMO OS ALUNOS SOBRESSAÍRAM NO TESTE DE REPRESENTAÇÃO DA TRIDIMENSIONALIDADE?}

O professor Gildo Montenegro, tomando como ponto de partida o trabalho teórico de pedagogos, psicólogos e cientistas russos da década de $1960^{10}$, desenvolveu um teste, aplicando-o para seus alunos, ingressantes do curso de Arquitetura e Urbanismo da Universidade Federal de Pernambuco (UFPE). A prática foi realizada no $2^{\circ}$ semestre de 2003 e, em 2005, publicado em formato de livro, sob o título "Inteligência visual e 3-D". O mesmo foi tomado como referência e, de igual modo, executei avaliação similar.

O teste dessa pesquisa foi aplicado no primeiro dia letivo, do semestre um, de 2020 (fevereiro); na Disciplina de "Perspectiva e Sombra", Curso de Arquitetura e Urbanismo, UNIPAC/Barbacena, estando presentes 34 alunos. A identificação quanto ao nome não foi obrigatória, devendo-se apenas responder a experiência quanto ao tema. Da descrição: 17alunos eram referentes ao primeiro período de curso; 1 do segundo período e 16 do terceiro período. Com essa variação, além do conhecimento prévio trazido pelos discentes iniciantes, também tornou-se possível averiguar o nível de absorção de técnicas de representação da tridimensionalidade já trabalhadas (parcialmente), por mim, em disciplina ministrada anteriormente: "Desenho artístico à mão livre", 2019-01. Por essa via, a análise realizada a posteriori foi fracionada em dois grupos de igual número, 17 alunos. (SEVERINO, 2007).

\footnotetext{
${ }^{10}$ Entre eles: Menchiskava, Zelenin, Dorf, Fedorovich, Vas'Kova, Marchenko, Tevlin e outros da Academia de Ciências Pedagógicas de Moscou.
} 
Cada aluno recebeu uma folha de papel no tamanho A4, a qual deveria ser dividida, mentalmente, em uma fração de 6 unidades. Cada quadro comportaria uma representação conforme lista apresentada na lousa: 1.taça de vidro com líquido até a metade; 2.mesa retangular; 3.casa; 4.melão cortado no prato; 5.dado; 6.livro. Alguns dos objetos diferiram do teste aplicado pelo professor Montenegro; deste foram postulados: copo com líquido até a metade; mesa retangular; avião; melão no prato; tijolo; livro. Em ambos os testes, os esboços foram realizados sem a utilização de instrumentos técnicos de desenho, adotou-se apenas lápis e borracha. Ao partir para análise, a planilha seguinte demonstra uma visão ampla e resumida dos resultados:

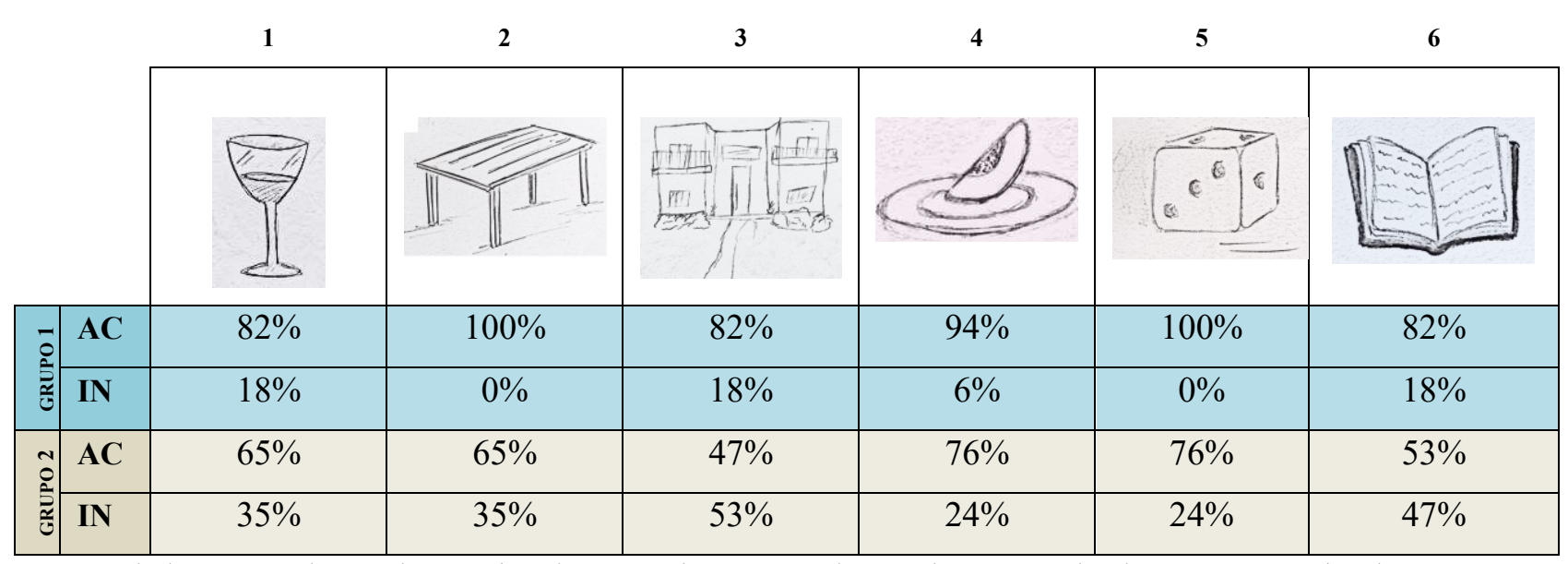

Tabela 1 - Nível Superior, Ensino de "Desenho", Curso de Arquitetura e Urbanismo, UNIPAC/Barbacena.

$\mathrm{Na}$ descrição, o "grupo 1" refere-se (então) aos alunos do $3^{\circ}$ período e o "grupo 2", basicamente, alunos do $1^{\circ}$ período. O balanço dado em porcentagem indica os desenhos considerados aceitáveis (AC) e os de incorreções mais acentuadas (IN). Na sequência e, em forma de texto, vêm as discussões.

\section{$1^{\circ}$ Desenho: Taça}

Nessa representação gráfica, dos 17 alunos do grupo 1, 82\% (14) alunos apresentaram grau aceitável de acerto, para $65 \%$ (11) alunos do grupo 2. O restante apresentou um maior grau de incoerência. O acerto concentrou-se no reconhecimento da elipse presente na borda e na base da taça, bem como no líquido. Em alguns casos, essas foram indicadas por uma linha reta, o que sugere uma angulação diferente de perspectiva (vista frontal). De acordo com Montenegro pode ser um indício de dificuldade no traçado (questão explicita em outras representações, com destaque para a mesa e para a casa). O grau de incoerência na representação, destaca-se pela falta de proporção e harmonia do todo (borda, bojo, haste e base). Averigua-se, também, o nível de dificuldade em manter o equilíbrio do traço (imagem espelho) entre lado direito e esquerdo da forma.

\section{$2^{\circ}$ Desenho: Mesa retangular}

Essa representação obteve um índice maior de imagem aceitável no grupo 1, configurou a totalidade (100\% - 17 alunos), enquanto o grupo 2, manteve o mesmo índice: $65 \%$ (11 alunos). No grupo 1,4 alunos (24\%) realizaram o desenho em vista frontal, para $12(70 \%)$ do grupo 2 - angulação mais fácil de ser representada. Portanto, dos 34 desenhos totais (100\%), 16 alunos (47\%) buscaram um facilitador na representação; do restante: 16 alunos (mesma porcentagem, 47\%) aplicaram a projeção cilíndrica ou paralela, com maior ênfase na expressão cavaleira e $2(6 \%)$ se beneficiaram da projeção cônica, com o uso de 2 pontos de fuga. As incoerências se acentuaram, mais uma vez, na falta de proporção e harmonia da forma (relação tampo e pés, ainda que se reconheça tamanhos possíveis de 
mesa no mercado); também observa-se que não houve especificação de medidas/escalas para o desenho, nem a materialidade da massa - alguns acabaram por representar tampo transparente.

\section{$3^{\circ}$ Desenho: Casa}

Para essa representação permanece o maior nível de desenho aceitável no grupo 1 (já esperado): 82\% (14 alunos) para 47\% (8 alunos) do grupo 2. Dos 34 testes totais, 21 alunos (62\%) representaram a casa em vista frontal (11 alunos do grupo 1 e 10 alunos do grupo 2) - um índice considerado alto, por ser (conforme já dito) um perfil facilitador. A questão que mais chamou a atenção nessa representação gráfica indica, como se refere Montenegro, "a persistência do desenho infantil"; sendo causada pela ausência de instrução desenhística. De minha experiência, já conhecendo os alunos do grupo 1, posso, firmemente, acrescentar que se refere, também, "não praticarem o conhecimento adquirido na quantidade de tempo considerada ideal". Pesquisadores como Braukman (1991, apud MONTENEGRO, 2005, p.11) identificam que a habilidade de representação espacial é perfeitamente aprendível, com uma melhoria extremamente significativa, após $18 \mathrm{~h}$ de treinamento intensivo e com o uso de modelo. Do grupo 1, identifico facilmente as instruções já fornecidas, mas não em grau totalmente aceitável, ou melhor, não há uma homogeneidade entre os alunos quanto a absorção do conteúdo aplicado em sala de aula.

\section{$4^{\circ}$ Desenho: Melão cortado no prato}

"Em cada cabeça, uma sentença; ou um desenho...", expressa descontraidamente Montenegro. Replico, por observar que no conjunto das representações e, em particular, nessa (de número 4), houve uma grande variação do modo de interpretar o que se pediu. Do total, 29 alunos (16 do grupo 1 e 13 do grupo 2) foram bem sucedidos, para 5 (15\%), com um nível de insatisfação grande. No geral, 6 optaram pela vista superior, 26 pela vista lateral e 2 não definidos.

\section{$5^{\circ}$ Desenho: Dado}

Essa foi a figura com o maior índice de acertos: total de 30 alunos (17 do grupo 1 e 13 do grupo 2). A vista preferida foi a cavaleira: 24 desenhos (meio a meio entre os grupos), seguindo-se de 6 representações isométricas ou de valor aproximado e 1 de caráter indefinido. Como à luz de Montenegro, possivelmente, o alto índice de acerto pode estar contido no fato de ser um objeto de conhecimento comum, de apreensão rápida do olhar e sem grande margem de variação corpórea. A mesma descrição estaria para a mesa, no entanto, na pesquisa de Gildo M. houve uma enorme discrepância quanto ao resultado de ambas - questão que o professor confessou não saber explicar. O mesmo não ocorreu no teste desta pesquisa - aqui, houve igualdade no grupo 1 e no grupo 2 , uma pequena variação para menos, embora identifica-se que o objeto "tijolo" em Gildo M. fora substituído pelo objeto "dado"; mas todas prismáticas e ortogonais. Destaca-se, ainda, a igualdade de acertos com o teste 4 (melão no prato), somente grupo 1 .

\section{$6^{\circ}$ Desenho: Livro}

A tridimensionalidade está bem aparente em 23 desenhos, 68\% (14 do grupo 1 e 9 do grupo 2); no entanto, houve uma variação entre a representação gráfica do livro, estando entre aberto e fechado, de pé ou inclinado (tal orientação não foi especificada). Há nesse, certos questionamentos como em Montenegro, entre os mesmos destacam-se: por que há diferenciação considerável de erros e acertos entre a representação do livro, do dado, da mesa e da casa? Para esse teste, igualdade apenas do grupo 1, em relação ao grafismo com a casa. Outra: por que houve alunos que realizaram a representação 
de forma brilhante, com variadas posições do livro e acréscimo até de um elemento de apoio (armário), como se demonstrasse confiança no que se faz. Tal ação, indica-me: qual você prefere? Enquanto muitos me passam a impressão de um caráter amedrontado e inseguro. Será que para alguns, o que prevaleceu diante do teste não foi o temor emocional, provocando o bloqueio do intelecto?

Gildo Montenegro deixa claro que o objetivo do teste por ele aplicado é compreender a deficiência dos alunos quanto à capacidade da representação gráfica. Todavia, suas preocupações perpassam o nível superior e expandem para a instrução escolar do indivíduo como um todo. Isso pode ser claramente identificado, pois, além dos autores já citados, baseia-se em referências como Jean Piaget e Vygotsky - o que nos leva até mesmo a um nível anterior à educação básica, isto é, nos transporta ao desenvolvimento intelectual infantil; linha de estudo daqueles (ainda que com pontos de vista conflitantes). Assim sendo, os esforços de Gildo caminha-se na crença que o cérebro e a mente humana são dinâmicos, como à luz de Vygotsky e não limitado por "estágios específicos de desenvolvimento", como em Piaget. Gildo M. também reconhece a possibilidade de ampliação do que apresenta, sendo "um caminho a ser percorrido [tanto] por pesquisadores [quanto] por professores de sala de aula, em estreita colaboração." (Cf. MONTENEGRO, 2005, p.5).

Por conseguinte, no sentido dessa sinergia e amplitude, na planilha seguinte, apresento uma síntese do mesmo teste aplicado anteriormente, mas, agora, na educação básica. Período: fevereiro de 2020. É propício firmar ser, de igual modo, fruto de experiências pessoais, sendo, pois, um nicho de minha atuação. Dessa base, é acrescido o ensino a nível superior, mas, agora, referente ao curso de Pedagogia (UNIPAC/Barbacena), disciplina "Metodologia do Ensino de Arte" e outras.

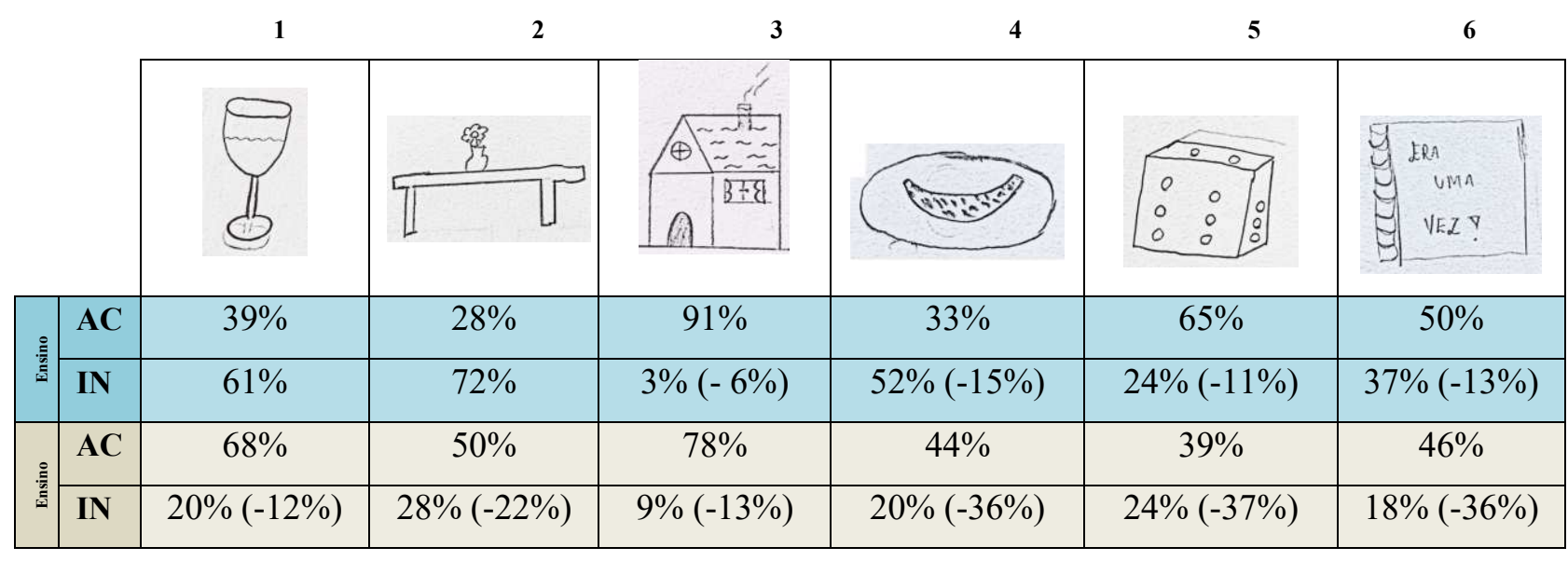

Tabela 2 - Educação Básica (Ensino Médio e Fundamental II), Ensino de "Desenho", Componente Curricular Arte.

Essa segunda planilha foi analisada em um agrupamento que reúne 108 desenhos ${ }^{11}, 54$ referentes ao ensino médio e 54 ao ensino fundamental - dois níveis diferentes da educação básica. Uma análise mais detalhada será apresentada em outro estudo. Neste, atenta-se para o fato claramente perceptível que a falta de domínio na representação se amplia de modo considerável, comparando-se a verificação anterior, havendo (pois) necessidade de certo afrouxamento quanto ao julgamento do grafismo como: "aceitável" (AC) e "maior incorreção" (IN). A própria opção pelo curso superior de Arquitetura já sugere uma aptidão à área, sendo identificada (acredito) por certas representações gráficas que se destacaram de forma extremamente positiva comparando-se ao conjunto. $\mathrm{O}$ contrário é reforçado pelo

\footnotetext{
${ }^{11} \mathrm{O}$ teste foi aplicado aos alunos que estavam presente em sala de aula. Ensino Médio: 35 alunos $\left(1^{\circ}\right.$ ano); 9 alunos $\left(2^{\circ}\right.$ ano) e 10 alunos ( $3^{\circ}$ ano). Ensino Fundamental: 5 alunos ( $6^{\circ}$ ano); 32 alunos ( $8^{\circ}$ ano) e 17 alunos $\left(9^{\circ}\right.$ ano). $\mathrm{O}$ número reduzido se deve ao início do ano letivo (fevereiro de 2020) e iminência de greve; refere-se a rede estadual de Ensino do Estado de Minas Gerais.
} 
número de alunos que não conseguiram (ou nem tentaram) realizar os desenhos; na planilha, tal fato é indicado pelas porcentagens negativas entre parênteses.

Gildo M., em seu livro, formula uma seção quanto ao que chamou de "figuras não convencionais e esquisitas", sendo esse caráter muito identificado nesse quantitativo. Em um sentido de finalização, destaco o esboço de número 3 (casa), com o maior índice de figuras representadas de forma aceitável; porém, quase todo o montante tratou-se do traço comum da "casa" da primeira infância: o perfil frontal, com telhado, janela e porta - recorte arraigado no imaginário universal. Quanto aos menores índices de aceitação, apresenta-se o número 2 (mesa) e 4 (melão cortado no prato). Aquela forma (mesa) se destaca pela falta de instrução das regras da perspectiva (alguns alunos arriscaram o uso do ponto de fuga, certamente, lembraram-se de aulas anteriores ${ }^{12}$, mas ainda não com qualidade na execução - seria a falta sistemática da prática. O que confirma a necessidade de certo quantitativo de horas no treino, como já discutido). Enquanto esta forma (melão cortado no prato), além do nível de dificuldade em desenhar a perspectiva de um prato (elipse), o melão pareceu-me um elemento não tão comum no repertório imagético dos alunos, por isso a dificuldade.

\section{CONSIDERAÇÕES FINAIS}

A situação paradoxal da dicotomia "manual e tecnológico" aplicado aos modos de representação da imagem figurativa no plano e cuja aplicação insere-se em áreas variadas, entre estas as, Artes Visuais e a Arquitetura; quanto à essa incursão, autores como Pedrosa Júnior (2009, p.236), salientam ser um modo de atuação da contemporaneidade, visto que na "busca do autoconhecimento" as diferentes disciplinas acabam por se apropriarem de materiais teóricos, metodológicos e práticas de outras áreas, confirmando, dessa forma, "que o conhecimento de si passa, necessariamente, pelo conhecimento do outro", o que justifica a junção de análise estabelecida nesse estudo; mesmo porque Arte e Arquitetura sempre estiveram juntas no decorrer dos tempos e não apenas nessa análise.

Da mesma forma (há de se convir) quanto à afirmativa: "desde os anos de 1960, vivemos numa cultura de mass media, na qual a apropriação, a divulgação e a própria produção das imagens acontecem de forma vertiginosa" o que leva "o ensino dos meios e modos de representação realizado pelas mãos sofrerem abalos significativos"; comprova-se através do estudo que, na verdade, ainda que em graus diferentes a depender das épocas, esse fato sempre coexistiu - não sendo uma característica própria de agora. E, apesar de toda a facilidade vinda através das novas tecnologias, tornou-se notável ser impraticável seu uso sem o alicerce da habilidade manual; e esta (por sua vez) deve ser fortalecida em uma construção conjunta de percepção espacial e de sensibilização criativa (eis a diferenciação entre Naturalismo, Idealismo e Expressionismo). Portanto, como à luz de Griz; Carvalho e Peixoto (2007, p. 4): em meio universitário não se trata de ensinar apenas técnicas de representação, mas os fundamentos, os conceitos e sua correta aplicação, "dando ao aluno a possibilidade de optar pela ferramenta que mais for apropriada para cada ocasião". Ora afirmam os especialistas, o profissional da arquitetura, em várias situações, podem ser solicitados à produção de croquis rápidos, não estando na presença do recurso computacional, além de que o projeto arquitetônico pode ser fortemente agilizado a partir de uma desenho prévio realizado à mão.

Observa-se, ainda a partir deste estudo, que o embasamento histórico aplicado a uma disciplina ("Perspectiva e Sombra", Curso Arquitetura e Urbanismo, como no caso) de caráter iminentemente prático, além de estimular o interesse do aluno pela aquisição de habilidades representacionais, aumenta a oportunidade de crescimento cultural, o contato com inúmeros exemplares da Arte e da Arquitetura, que poderão ser tomados como ponto de referência para futuras criações autorais, bem como tomar ciência dos longos processos e embates da conquista da representatividade pela

\footnotetext{
${ }^{12} \mathrm{~A}$ temática foi desenvolvida por mim, no ano de 2019; mas não em $100 \%$ dos analisados.
} 
humanidade (seja na dimensão manual, tecnológica ou conceitual) circunstanciando, pois, de modo maduro, esse lugar ao qual (a partir da formação) o discente se inserirá profissionalmente.

Por fim, identifica-se que tal ensino, ao acontecer acrescido pela abrangência da pesquisa, há um fortalecimento no processo de ensino-aprendizagem como um todo, uma vez que a análise sobre os resultados nos leva a trabalhar diretamente nas deficiências (dos alunos) apontadas pelo teste, o que gera eficácia nos resultados. Espera-se que, ao final do semestre letivo, novo teste seja aplicado de modo que a investigação continue. Acrescenta-se, também, que a efetivação de uma pesquisa, ao se transformar em texto, há uma transposição dos níveis de sala de aula, tornando-se um instrumento de compartilhamento entre os pares. Trata-se (portanto) do fortalecido do binômio "ensino-pesquisa", no qual o aluno e o professor passam de consumidor para construtor do conhecimento. Autores como Caracini (1998), em Foucault, confirmam a prática como inspiradora da teoria, "como criadora em relação a uma forma futura de teoria”. (Cf. CORACINI, 1998 apud FOUCAULT, 1979, p. 69).

\section{REFERÊNCIAS}

ALCANTARA, Marlon Cesar. História da Ciência, Filosofia e Arte na Holanda do Século XVII: construindo um módulo para o ensino dos instrumentos óticos. Dissertação (Mestrado). Programa de Pós-Graduação e Ensino de Ciências e Matemática do Centro Federal de Educação Tecnológica Celso Suco da Fonseca - CEFET/RJ, 2011.

BARROS, José D’Assunção. A arte é coisa mental. In: Revista Poiésis, n. 11, p. 71-82, 2008. BRION-GUERRY, Liliane. Jean Pélerin Viator: Seu lugar na história da perspectiva. Paris, Société d'Edition les Belles Lettres, 1962.

CARACINI, Maria José R.F. A Teoria e a Prática: a Questão da Diferença no Discurso sobre e da Sala de Aula. DELTA vol. 14, n. 1. São Paulo Feb., 1998.

DENISON, Edward. Arquitetura:50 conceitos e estilos fundamentais. SP: Publifolha, 2016. DOSSE, François. G. Deleuze e F. Guattari:Biografia Cruzada. Porto Alegre: Artmed, 2010.

GRIZ, CARVALHO, PEIXOTO. Desenho de perspectiva e história da Arquitetura: em busca de uma Interdisciplinaridade. Graphica Curitiba, 2007.

HOCKNEY, David. O conhecimento secreto. São Paulo: Cosac \& Naify, 2001.

KRAUSS, Rosalind. A escultura no campo ampliado. Gávea, Rio de Janeiro, n. 1, 1984 [/1979].

LEMOS, Carlos A. A imitação em Aristóteles. Anais Filosofia Clássica, v. 3 n. 5, p. 84-90, 2009.

MARCONDES. Luiz Fernando. Dicionário de Termos Artísticos. RJ: Pinakotheke, 1998.

MONTENEGRO, Gildo A. Geometria descritiva. São Paulo: Blucher, 2016.

MONTENEGRO, Gildo A. Inteligência visual e 3-D. São Paulo: Blucher, 2005.

OSTROWER, Fayga. Universo da Arte. Rio de Janeiro: Elsevier, 2004.

PEDROSA JR, N.C. Estudos Interartes: Uma Introdução. Raído, Dourados,v.3,n.5, jan./jun. 2009.

POLLIO, Vitrúvio. Tratado de Arquitetura. São Paulo: Martins Fontes, 2007.

SAITO, Fumikazu. Instrumentos de magia e de ciência: a observação mediada em telescópio segundo a perspectiva de Giambattista della Porta. Tese, 325f (Doutorado). Programa de PósGraduação em História da Ciência. Pontifícia Universidade Católica de São Paulo, 2008. 
SANTAELLA, Lucia. Linguagens líquidas na era da mobilidade. São Paulo: Paulus, 2007.

SEVERINO, Antônio Joaquim. Metodologia do trabalho científico. 23ª ed. SP: Cortez, 2007.

SMTIH, Ray. Manual Prático do Artista. Porto: Civilização, 2003.

SOGABE, Milton; LEOTE, Rosangella. Formação Docente. Rede São Paulo SEESP. SP, 2012.

VERASZTO et al. Tecnologia: Buscando uma definição para o conceito. Prisma.com, nº 7, 2008. 